\title{
Pendampingan Kader Posyandu Lansia di Suka Raya
}

\author{
Sulaiman, Lagut Sutandra, Yeni Vera, Anggriani \\ STIKES Siti Hajar Medan \\ man_fisioterapi@yahoo.co.id
}

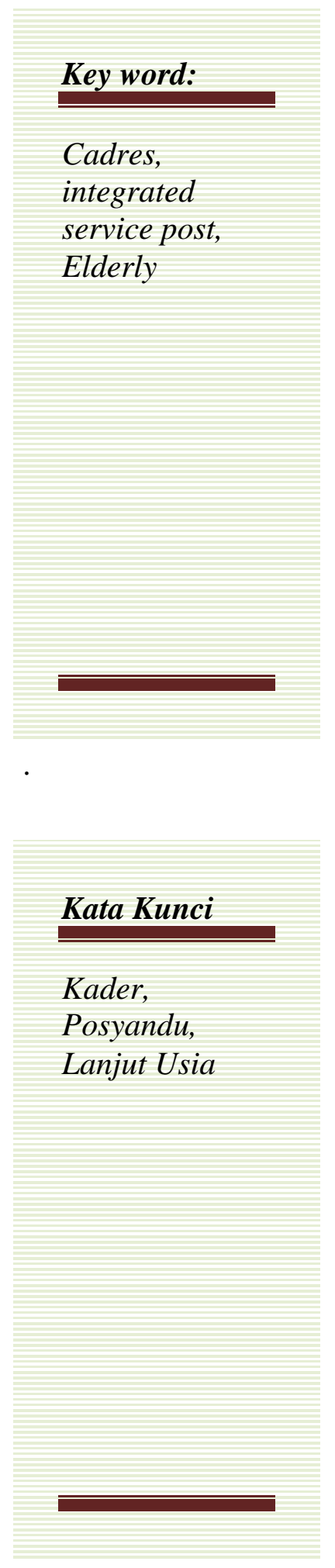

\section{Abstract}

Elderly integrated service pos is an integrated service post for elderly people (elderly) in a certain area that has been agreed by society. Cadres integrated service post have an important role in mobilizing elderly to come to integrated service post. In Village of Suka Raya the number of elderly as many as 338 people from the total population 4291 people. Activity Posyandu elderly in Villege of Suka Raya less desirable by elderly who really need basic health services, so many elderly in the Village of Suka Raya experiencing health disturbances. This community service uses methods of counseling, training, application and assistance in the use of infrared addressed at cadres integrated service post in Village of Suka Raya. The aim of this Community Service is that integrated service post cadres understand and are able to provide maximum service to the elderly who come to integrated service post. The results of this Community Service show that there is an increase in elderly visits to integrated service post by $30 \%$. It is expected that integrated service post cadres and elderly families can participate actively in helping to increase the elderly visit to the integrated service post of elderly.

\begin{abstract}
Abstrak
Posyandu lansia adalah pos pelayanan terpadu untuk masyarakat lanjut usia di suatu wilayah tertentu. Kader posyandu mempunyai peranan yang penting dalam menggerakan lansia untuk datang ke posyandu. Di Desa Suka Raya jumlah lansia sebanyak 338 jiwa dari total penduduk 4291 jiwa. Kegiatan Posyandu lansia di Desa Suka Raya kurang diminati oleh lansia yang sangat memerlukan pelayanan kesehatan dasar, sehingga banyak lansia di Desa Suka Raya mengalami gangguan-gangguan kesehatan. Pengabdian masyarakat ini menggunakan metode penyuluhan, pelatihan, penerapan dan pendampingan penggunaan infrared yang ditujukan kepada kader posyandu lansia di Desa Suka Raya. Tujuan Pengabdian Masyarakat ini adalah kader posyandu lansia paham dan mampu memberikan pelayanan yang maksimal kepada lansia yang datang ke posyandu lansia .Hasil dari Pengabdian Kepada Masyarakat ini menunjukkan bahwa terjadi peningkatan kunjungan lansia ke posyandu lansia sebesar 30\% Kader posyandu dan keluarga lansi turut berpartisipasi aktif dalam membantu peningkatan kunjungan lansia ke posyandu lansia.
\end{abstract}




\section{PENDAHULUAN}

Posyandu lansia adalah pos pelayanan terpadu untuk masyarakat usia lanjut di suatu wilayah tertentu yang sudah disepakati oleh masyarakat . Di Desa Suka Raya posyandu lansia kurang diminati oleh lansia yang memerlukan pelayanan kesehatan dasar, sehingga banyak lansia di Desa Suka Raya mengalami gangguangangguan kesehatan. (Depkes RI. 2013)

Dampak dari peningkatan jumlah sebanyak 338 lansia di Desa Suka Raya adalah masalah penyakit degeneratif yang sering menyertai para lansia, bersifat kronis dan multipatologis, serta dalam penanganannya memerlukan waktu lama dan membutuhkan biaya cukup besar. Oleh karena itu, untuk menarik perhatian, pemerintah terhadap kesehatan lansia, serta dampak dan tantangan kesehatan akibat penambahan jumlah populasi dengan cara menjalin kerjasama dengan pemerintah pusat, pemerintah daerah, organisasi kemasyarakatan, swasta dan organisasi internasional, untuk mendapatkan komitmen dalam upaya peningkatan penanganan masalah kesehatan dan penuaan. (Depkes RI.2013)

Sasaran program posyandu lansia di Desa Suka Raya adalah lansia usia 60 tahun ke atas dengan tujuan agar lansia siap menghadapi usia lanjut dengan mandiri dan sehat. Kegiatan pelayanan kesehatan di posyandu lansia hanya meliputi pemeriksaan aktivitas kegiatan sehari-hari (activity of daily living), penimbangan berat badan, pengukuran tinggi badan, pengukuran tekanan darah, penyuluhan kesehatan, pemeriksaan laboratorium sederhana, pemeriksaan status mental dan emosional, pengobatan sederhana dan upaya rujukan bila diperlukan. Kegiatan-kegiatan yang dilakukan oleh kader kurang menarik minat para lansia. Semua kegiatan di posyandu lansia dilakukan satu kali dalam sebulan.

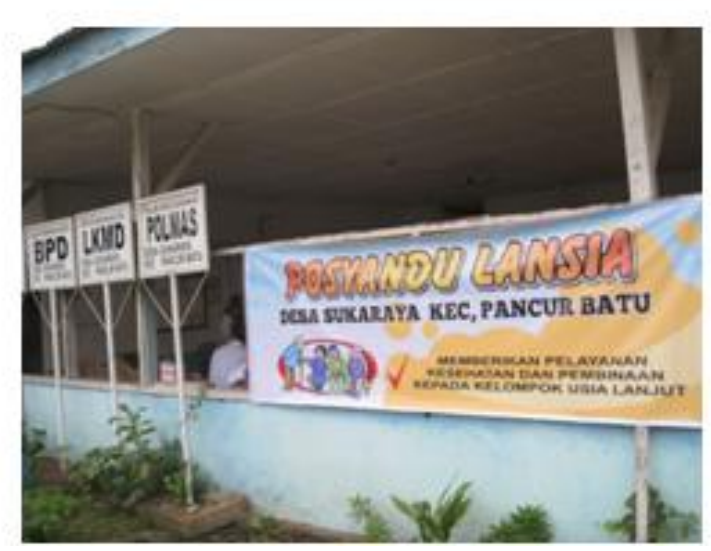

Gambar 1. Balai Desa Suka Raya (tempat kegiatan posyandu lansia)

Kader posyandu memegang peranan yang sangat strategis dalam upaya pemanfaatan pelayanan posyandu lansia perlu mendapatkan perhatian serius dan menjadi bagian dari strategi dalam peningkatan kesejahteraan lansia melalui upaya promotif dan preventif atau yang biasa disebut paradigma sehat. Mengingat fisik lansia yang lemah sehingga mereka 
tidak dapat leluasa menggunakan sarana dan prasarana maka upaya pemanfaatan pelayanan posyandu lansia yaitu dengan menyediakan sarana dan fasilitas khusus bagi lansia.

\section{Permasalahan Mitra}

Hasil Analisis situasi yang dilakukan tim pengabdian diketahui bahwa rata-rata kunjungan lansia ke posyandu hanya $12 \%$. Desa Sukaraya memiliki realisasi cakupan pemanfaatan posyandu lansia lebih kecil dibandingkan dengan desa lainnya disekitar Suka Raya, Data profil Desa Sukaraya Kecamatan Pancur Batu Kabupaten Deli Serdang Provinsi Sumatera Utara memaparkan bahwa pada umumnya penduduk asli adalah suku jawa, jumlah lansia berusia 60 tahun ke atas sebanyak 338 jiwa dari total penduduk sebesar 4.291 jiwa. Namun jumlah tersebut tidak sejalan dengan jumlah kunjungan ke posyandu lansia. Kegiatan posyandu, dilaksanakan tanggal 15 setiap bulan diselenggarakan di balai desa dengan kegiatan senam, penimbangan berat badan lansia, pemeriksaan tekanan darah, pemeriksaan denyut nadi, konsultasi kesehatan dan pengobatan secara gratis yang biasanya diselingi dengan acara penyuluhan-penyuluhan tentang kesehatan.

Hasil wawancara dengan 2 orang kader posyandu mengatakan bahwa lansia yang ada di Desa Sukaraya pada umumnya terkena penyakit tekanan darah tinggi (hipertensi), pengeroposan tulang (osteoporosis) dan gangguan pada sendi (osteoarthritis). Para lansia tidak aktif ke posyandu tiap bulan sebagian disebabkan malas karena kegiatan posyandu lansia kurang menarik minat mereka karena kurangnya fasilitas kesehatan yang tersedia seperti vitamin dan makanan tambahan serta persediaan obat sangat sedikit. Kader posyandu di Desa Suka raya hanya 6 orang dan berpendidikan rata-rata tingkat SLTA kebawah. Mitra dalam pengabdian ini adalah kader posyandu lansia yang bertanggungjawab atas pemanfaatan posyandu lansia di Desa Suka Raya.

Pengabdian ini fokus pada peningkatan manajemen dan peningkatan kopetensi kader dalam meningkatkan pemanfaatan posyandu lansia di Desa Sukaraya Kecamatan Pancur Batu

Berdasarkan analisis situasi yang dilakuan tim pengabdian yang dilakukan terhadap kader posyandu lansia, terdapat permasalahan yang sangat serius yang 
dihadapi oleh kader posyandu lansia, permasalahan tersebut dapat dirincikan sebagai berikut :

1. Kader posyandu kurang mampu memberikan pelayanan kesehatan kepada lansia sehingga lansia tidak mau mengikuti kegiatan posyandu lansia, lansia merasa pelayanan kesehatan yang diberikan tidak dapat mengatasi masalah kesehatan mereka

2. Kader kurang mampu berkomunikasi dengan baik kepada lansia maupun dengan keluarga lansia, dikarenakan tingkat pendidikan kader masih rendah, rata-rata dibawah Sekolah Menengah Atas. Akibatnya penyampaian informasi kegiatankegiatan posyandu lansia tidak sampai dengan baik kepada para lansia dan keluarganya.

3. Kader posyandu lansia tidak memberikan kegiatan-kegiatan yang inovatif. Kegiatan yang dilakukan hanya monoton seperti timbang berat badan, senam lansia, dan pemeriksaan kesehatan sederhana sehingga lansia enggan datang.

4. Kader yang sangat sedikit ini tidak sebanding jumlah lansia yang begitu banyak yaitu 338 lansia, pelayanan jadi lambat, lansia terlalu lama

\author{
menunggu dalam mendapatkan \\ pelayanan kesehatan dan akhirnya \\ lansia tidak dapat dipantau \\ kesehatannya dengan baik.
}

\section{Permasalahan Prioritas}

Setelah melihat permasalahan yang di alami oleh mitra cukup banayak, perlu adanya gebrakan atau tindakan dari masyarakat sendiri. Untuk itu perlunya dilakukan pengbdian ini Desa Sukaraya Kecamatan pancurbtau Kabupaten Deli Serdang Sumatera Utara. Dari hasil diskusi bersama yang dilakuan tim pengabdian dengan kader posyandu lansia pada disepakati bahwa permasalahan yang menjadi prioritas kegiatan pengabdian di posyandu lansia adalah :

1. Manajemen Posyandu lansia yaitu Struktur organisasi yang kurang tegas dalam pembagian tugas dan kewajiban kader, Sarana dan prasarana kesehatan yang kurang memadai dan jumlah SDM yang sedikit. Jadwal kegiatan posyandu yang selalu berubah-ubah mengakibatkan lansia malas datang mengecek kesehatannya

2. Kompetensi Kader yaitu Kader kurang mampu memberikan penyuluhan kesehatan, dan kurang mampu berkomunikasi dengan baik dengan lansia maupun dengan keluarga lansia, dikarenakan tingkat 
pendidikan kader masih rendah, ratarata dibawah Sekolah Menengah Atas. Akibatnya penyampaian informasi kegiatan-kegiatan posyandu lansia tidak sampai dengan baik kepada para lansia dan keluarganya

3. Solusi yang diberikan kepada mitra adalah Peningkatan Kualiats Manajemen Posyandu dengan cara memperbaiki strutur organisasi, perbaikan pelayanan posyandu, menambah kegiatan kegiatan kesehatan pendukung lainnya. Karena tujuan dari pengabdian ini adalah meningkatkan pemanfaatan posyandu lansia yang selama ini tidak di manfaatkan oleh lansia.

4. Solusi selanjutnya adalah peningkatan kompetensi para kader posyandu lansia dengan cara memberikan pelatihan teknik komunikasi, pelatihan penyuluhan kesehatan pelatihan teknk dasar penggunaan Infrared. Kemudian memberikan pendampingan kepada kader sampai para kader paham mempraktekan apa yang telah dibberikan oleh tim pengabdian.

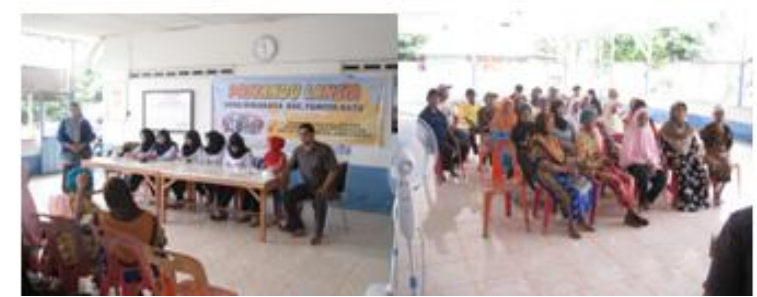

Gambar 2 Memberikan penyuluhan/ ceramah

\section{METODE PELAKSANAAN}

Rancangan kegiatan untuk mencapai tujuan adalah perencanaan (panning), pelaksanaan (action), evaluasi (evaluation dan tindak lanjut (. follow up). Secara detail metode dan mekanisme pelaksanaan kegiatan pengabdian ini dapat tim uraikan sebagai berikut:

1. Analisis lapangan yaitu menidentifikasi permasalahan yang terjadi di posyandu lansia Suka Raya

2. Membuat kesepakatan dengan mitra dilakukan diawal sebelum dilakukan pengabdian dengan kader posyandu lansia berupa penandatanganan surat peryataan kesediaan dukungan pelaksanaan PKM

3. Metode penyuluhan/ceramah unutk memberikan pelatihan teknik penyuluhan kesehatan yang baik dan benar kepada kader sehingga dapat memberikan informasi-informasi yang tepat kepada lansia dan keluarganya

4. Metode praktek dengan penerapan teknologi penggunaan infrared Memberikan pelatihan teknik dasar 
penggunaan alat infrared kepada kader dan sekaligus penanganan langsung fisioterapi kepada lansia, sehingga pada saat kader memberikan teknik dasar penangan terapi dengan alat infrared kepada lansia, kader tidak mengalami kesulitan lagi

5. Metode Pendampingan, dengan cara memberikan pendampingan selama 6 (enam) bulan berturut-turut agar apa yang telah diberikan oleh tim pengabdian dapat terlaksana dengan baik.
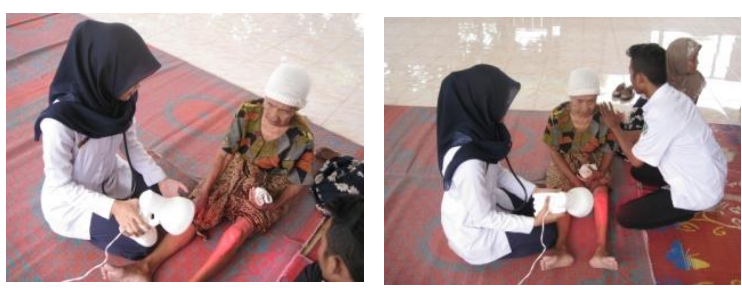

Gambar 3 memberikan sinar infrared kepada lansia

\section{HASIL DAN PEMBAHASAN}

Dari hasil kesepakatan dengan mitra dalam Pengabdian Kepada Masyarakat ini memberikan dampak yang sangat signifikan ke pada mitra. diantaranya adalah:

1. Kader posyandu lansia telah data memberikan penyuluhan/ ceramah kesehatan dengan baik kepada lansia dan juga keluarga lansia, Selama ini kurang memiliki pengetahuan terhadap pentingnya kesehatan bagi lansia. Keluarga jadi bersedia untuk mengantar jemput lansia di posyandu lansia. Dengan sehatnya lansia tidak menganggu pekerjaan dari keluarga lansia sendiri. Buku saku teknik komunikasi yang diberikan oleh tim pengabdian sangat membatu kader dalam kegiatan sehari-hari.

2. Perbaikan struktur organisasi yang baik menjadikan kegiatan posyandu tidak tertumpu pada seseorang saja. Hal ini dapat dilihat dari evaluasi yang dilakukan tim selama pendampingan

3. Para kader telah mampu menggunakan lampu infrared berserta perawatan dasar alat infrared. Infrared ini sangat membantu kader dalam meberikan pelayan kesehatan kepada lansia. Kegiatan-kegiatan yang monoton selama ini dapat di uarikan dengn memberikan sinar infrared kepada lansia. Hasilnya lansia lebih aktif lagi dalam mengikuti kegiatan posyandu.

4. Perubahan karakter kader posyandu yang selama ini memberikan pelayanan kepada lansia sekedarnya,melepaskan tanggungjawab, dapat berubah dengan baik dengan memberikan pelayanan secara inovatif. 


\section{SIMPULAN}

Setelah dilakukan kegiatan Pengabdian di

Desa Suka Raya tim dapat mengambil kesimpulan sebagai berikut :

1. Terjadi peningkatan pelayanan kader kepada lansia berupa penambahan pelayanan kesehatan berupa infra red, peningkatan kunjungan dari $12 \%$ menjadi $30 \%$ kunjungan lansia.

2. Kader mampu menggunakan Infra red dengan baik sehingga manfaatnya dapat dirasakan oleh lansia

3. Terjadi peningkatan kunjungan lansia dari $12 \%$ menjadi $30 \%$ kunjungan perbulan

4. Kader dapat melakukan penyuluhan dan komunikasi dengan baik dibuktikan dengan meningkatnya kunjungan lansia.

\section{UCAPAN TERIMAKASIH}

Tim $\begin{array}{cr}\text { Pengabdian } & \text { Kepada } \\ \text { Masyarakat } & \text { mengucapkan }\end{array}$ banyak
terimakasih kepada Stikes Siti Hajar
Melalui LPPM, berkat bantuan dana dan
kepercayaan yang di berikan, tim dapat
melaksanakan dengan baik. Semoga tahun
depan dapat diberi kepercayaan kembali
untuk kegiatan lainnya

\section{DAFTAR PUSTAKA}

Kemenkes RI.Gambaran Kesehatan Lanjut Usia di Indonesia. Jakarta: 2013.
Kementrian Kesehatan RI. Menuju Tua: Sehat, Mandiri dan Produktif. "Kesehatan yang Baik Memperpanjang Usia dan Kehidupan" Panduan Peringatan Hari Kesehatan Sedunia, 2012.

Maryam S. Asuhan Keperawatan pada Lansia, Jakarta: Trans Info Media; 2012.

Rosidawati. Mengenal Usia Lanjut dan Perawatanya, Jakarta: Salemba; 2008

Tamher S. dan Noorkasiani. Kesehatan Usia Lanjut dengan Pendekatan Asuhan Keperawatan. Jakarta: Salemba Medika; 2011.

Muzakkir, M. (2013). Faktor-Faktor Yang Berhubungan Dengan Kinerja Kader Posyandu Di wilayah Kerja UPTD Puskesmas Kaledupa Kecamatan Kaledupa Kabupaten Wakatobi Propinsi Sulawesi Tenggara. Jurnal Ilmiah Kesehatan Diagnosis, 2(2), 136-142.

Setyatama, I. P. (2012). Hubungan Pengetahuan dan Motivasi Kader dengan Peran Kader Posyandu Lansia di Desa Kangkung Kecamatan Mranggen Kabupaten Demak. Jurnal Dinamika Kebidanan, 2(2). 